\title{
DELIVERING ON INFRASTRUCTURE MAINTENANCE FOR SOCIO-ECONOMIC GROWTH: EXPLORATION OF SOUTH AFRICAN INFRASTRUCTURE FOR A SUSTAINED MAINTENANCE STRATEGY
}

\author{
DEENA GOVENDER \\ Trans-Caledon Tunnel Authority, South Africa
}

\begin{abstract}
In South Africa (SA), similar to nations globally, the prevailing tangible link between people and the state is public infrastructure. Infrastructure is an essential enabler for socio-economic growth in communities and ultimately for a country. In this regard, infrastructure, being the backbone of a nation's prosperity, demands effective maintenance for optimum delivery of much-needed services. Currently, SA infrastructure is in a state of rapid deterioration and is adversely affecting economic growth. A significant quantity of SA infrastructure is on a path of dysfunction and collapse, due to deficiencies in maintenance practices and strategies. From the birth of democracy, the SA government has pursued socio-economic transformation and delivery of basic services to constrict the broadening boundaries of disparity. In this regard, the National Infrastructure Plan (NIP) was prioritized by government, in delivering strategic catalytic infrastructure projects. The NIP was highlighted as a key initiative in unlocking opportunities that generate inclusive economic growth, curb joblessness and poverty, create entrepreneurial opportunities, and mitigate population and urban expansion. Socio-economic transformation benefits from spending on new infrastructure is not being realised as initially anticipated. In this context, SA is currently in a state of weakening economic growth, with further amassed levels of joblessness, unremitting poverty and inequality. Due to investor reluctance, solicitation of strategic infrastructure funding is progressively becoming a debilitating challenge in all government institutions. Exacerbating circumstances further is the substandard functionality of existing infrastructure following compromised maintenance practices. This study of the state of infrastructure is to better understand principal reasons for infrastructure functionality regression. Furthermore, investigations into progressive maintenance strategies is focused upon. Recommendations are made for enhanced maintenance strategies to capitalize on infrastructure maintenance opportunities and important socio-economic growth imperatives.
\end{abstract}

Keywords: South Africa, infrastructure, maintenance, socio-economic, strategies.

\section{INTRODUCTION}

"Good roads, canals, and navigable rivers, by diminishing the expense of carriage, put the remote parts of the country more nearly upon a level with those in the neighbourhood of the town. They are upon that account the greatest of all improvements" [1].

Providing infrastructure for communities and the economy is one of the leading ways South Africa will realise inclusive and jobs-rich growth. Quality, affordable infrastructure raises economic productivity, permits economic expansion and allows marginalised households and communities to take advantage of new opportunities [2].

Efficient public infrastructure enriches the quality of life of people and supports a healthy economy through quality services and utilities like public roads, schools, clinics, water and sanitation or electricity services. The condition of infrastructure relates directly to efficiency of the service it provides to all residents. As such, it is a long-term investment deserving of protection and care, by both the State and the people who use it. 


\section{OBJECTIVES AND METHODOLOGY}

This paper looks at South African public infrastructure maintenance and its impact on socio-economic growth. The purpose of the paper is four-fold, comprising: to review public infrastructure maintenance strategies; to better understand key reasons for infrastructure regression; to draw lessons from the outcomes; and to make recommendations for improved infrastructure maintenance in South Africa and other countries.

The objective of the research is to inform and describe earlier public infrastructure maintenance initiatives by government, post the 1994 SA democracy, relative to the present state of public infrastructure. With respect to maintenance practices and strategies, the intention is to signal reformed approaches in raising the significance of infrastructure maintenance delivery to an equal footing with that of new public infrastructure development and simultaneously satisfying SA's thirst for new job opportunities as well as promoting social and economic growth imperatives.

This paper followed a desktop qualitative research, on the state of infrastructure and maintenance thereof. Key sources of information include industry publications on infrastructure, journal articles and technical reports on infrastructure. The author's job responsibilities and knowledge of the NIP evolution contributed to the research construct. The paper also benefited from a one day knowledge sharing seminar pertaining to infrastructure maintenance in South Africa. The session was attended by infrastructure specialists and project managers who deliberated extensively on current maintenance practices and challenges, as well as opportunities for improvement.

\section{CHALLENGES FACED BY NEW AND EXISTING INFRASTRUCTURE}

Developing infrastructure in many countries confronts two common challenges. First, investing wisely and effectively in infrastructure is complicated. The technical issues of choosing the most beneficial projects are often overshadowed by political considerations.

Second, in many countries globally, public resources are strained by years of slow growth and rigid social welfare spending commitments. While private investment in infrastructure has increased substantially since the 1990s, in many cases this has not been sufficient to compensate for declining public investment [3].

The above problems experienced in Brazil is comparable to some of the issues that add to current South African socio-economic circumstances. Infrastructure services backlogs continue to be a concern and a political priority, a more critical issue is that of the condition of South Africa's existing infrastructure assets, much of which are nearing, or have reached the end of their useful lives [4].

As demonstrated globally, spend on new infrastructure relates to direct and indirect jobs through employment in new business enterprises created as a spin-off from new infrastructure developments. In light of SA's poor sovereign credit rating, raising capital in order to mobilise new infrastructure development has been the Achilles heel of the economy in the past few years.

Complicating matters further, is the growing disjunction in the relationship between the private and public sectors, which is causing the private sector to be a bit shy to invest, right now. Even so, there are investors keen to develop and get involved in projects across the country. Overall, the private sector needs stability - which will come from clear government policy and leadership - in order to feel confident about investing. The market is eagerly awaiting clarity on some key policy issues [5].

Understanding the challenges faced in developing new infrastructure within the context of a weakening economy, of equal importance is the status of existing infrastructure in SA, 
which has progressively been falling short in functionality and efficiency due to poor maintenance practices.

In some sectors, existing infrastructure is in good to satisfactory condition, for example ports, national roads and airports, however, infrastructure in the remaining sectors are generally at risk of failure and collapse [6].

With specific reference to the electricity and water infrastructure sectors, which are most critical to SA's prosperity, are in need of urgent interventions. Efficient, cost effective service delivery is a major bone of contention in many spheres of SA that plague social and economic growth. Unreliable services owing to poor governance, resourcing and business practices within municipalities and State-Owned Enterprises (SOEs) are experiencing escalating operational costs in delivering much needed basic services to communities and businesses alike. Although services costs continue to increase, the efficiency in service delivery continues to decline.

\section{STATE OF SOUTH AFRICAN PUBLIC INFRASTRUCTURE}

Continued development of new infrastructure for the South African people is central to economic health and sustained socio-economic growth. In the same breath, good maintenance of infrastructure complements infrastructure longevity and efficiency and will help sustain a good economy and uplift society, thereby sustaining the quality of life for many.

South Africa does not have a legislature sanctioned process in a way of comprehensively auditing all public (social and commercial) infrastructure against quality and efficiency in the delivery of services. For example, the Audit Report by Infrastructure Australia, takes a strategic approach to assessing the nation's infrastructure needs and examines the drivers of future infrastructure demand, particularly population and economic growth. This provides an assessment of the value-add, or direct economic contribution of infrastructure. It also considers the future demand for infrastructure over a period of 15 years, and delivers an evidence base for further gap analysis, over the long term [7].

In 2006, the South African Institute of Civil Engineering (SAICE), in partnership with the Council for Scientific and Industrial Research (CSIR), had released the first Infrastructure Report Card (IRC). The IRC provides an assessment which rates the condition of public infrastructure in South Africa through a grading system. The IRC through a desktop study informs the status of all public infrastructure with respect to condition and efficiency in service delivery. There have been subsequent IRC's published by SAICE in 2011 and 2017.

The purpose of the IRC is to draw the attention of government, and of the public at large, to the importance of maintenance, and to factors underlying the condition (state of repair or disrepair) of SA infrastructure.

The IRC consists of a five-point scale, denoted A+ to E-, and has been used for the grading. At one extreme, SA infrastructure is comparable to the best in the world (Grade A), while on the other end, we have infrastructure that is in a state of disrepair or failure (Grade E), exposing the public to possible health and safety hazards.

Infrastructure from all public sectors (i.e. roads, rail, airports, ports, education, health care, solid waste management, waste water and water) were rated, and received an overall grading of D+ for the 2017 SAICE IRC. This grading lies at the upper end of the category - "At Risk of Failure". Compared to an overall SAICE IRC grading of C- in 2011, which can be said to be influenced by the 2010 world cup stadia and related infrastructure upgrades. The overall grading for the SAICE IRC 2017 indicates very poor infrastructure conditions with a declining outlook for SA's infrastructure. 
4.1 Traditional public infrastructure for social development and economic growth

While not drawing attention away from other infrastructure sectors that are also significant to socio-economic growth, it is important to highlight key infrastructure sectors in SA that are presently under enormous strain. This, being the water and electricity infrastructure sectors which for the past decade have been in perpetual decline, as such, sustaining reliable and cost-effective service delivery is proving to be an enormous challenge.

\subsubsection{Electricity}

The public sector continues to invest in infrastructure, with particular focus on new construction related to electricity generation. Infrastructural spend also underpins some of the goals of the National Development Plan (NDP) [8], in particular the provision of service delivery and infrastructural development [9].

Eskom, is by far the principal of SA's many SOEs. Eskom dominates the electricity market for energy generation, transmission and distribution by supplying 95\% of SA's electricity usage. The utility, currently in crisis, is now the greatest risk to the prosperity of the SA economy.

In 2016, Eskom topped the list as the largest capital spender in public-sector entities - the power utility contributed $25,7 \%$ (R73 billion) to total capital expenditure. Eskom is in an estimated R450 billion in debit, the SOE is in this predicament due to poor governance, management and is fraught with allegations of corrupt dealings.

SA's ability to deliver electricity services is compromised. Operating costs are too high and it cannot afford paying its debts due to not generating enough cash to pay even the interest on its debt.

Eskom has been implementing steep tariff increases in recent years, but these have driven some customers and businesses off-grid and shut others down. Eskom's sales have been declining by about $1 \%$ per annum. The less it sells, the higher the tariff it wants, and the less it sells - the utility death spiral [10].

\subsubsection{Water}

Similar to the woes of Eskom, public water and sanitation sector infrastructure is in crisis. This sector is managed largely by the Department of Water and Sanitation (DWS) and also by municipalities. Sector issues stem from inappropriate functions of: operations and maintenance of municipal infrastructure; funding models; contract management; revenue management; affordability and revenue flows; water pricing; institutional models [11].

This sector is of deepening concern caused by insufficient water maintenance practices and investment, aging infrastructure that is operated to a point of collapse. Loss of skilled human resources have largely contributed to the deterioration of infrastructure. Moreover, poor governance, inappropriate decisions being adopted, indecision on crucial issues and corruption allegations have further contributed to the downward spiral of water and sanitation service delivery.

This crisis is having substantial negative effects on economic growth and on the well-being of the people in SA. To provide further context, the following issues are the result of challenges faced by the DWS and are highlighted in the National Water and Sanitation Master Plan: 14.1 million people do not have access to safe sanitation; only $64 \%$ of households have access to a reliable water supply service; $56 \%$ of waste water treatment works and $44 \%$ of water treatment works are in a poor or critical condition $-11 \%$ are dysfunctional; more than $50 \%$ of South Africa's wetlands have been lost, and of those that remain, $33 \%$ are in poor ecological condition; only $5 \%$ of agricultural water used, is by black 
farmers; $41 \%$ of municipal water does not generate revenue $-35 \%$ is lost through leakage; municipalities are losing about 1660 million $\mathrm{m}^{3}$ per year through non-revenue water - at unit cost of R6/ $\mathrm{m}^{3}$ this amounts to R9.9 billion each year; R33 billion more is needed each year for the next 10 years to achieve water security [12].

\section{PLANNING FOR INFRASTRUCTURE MAINTENANCE}

Globally, the relevance of new infrastructure development in supporting social and economic growth is well recognised. Similarly, in SA this sentiment also holds true in government. Infrastructure maintenance on the other hand, being recognised as a driver of change in society and the economy, has not been prominently intensified compared to new infrastructure.

SOEs and municipalities are responsible for the implementation of a vast array of public infrastructure projects. However, once construction is complete and infrastructure is commissioned, appropriate maintenance should trail closely behind to ensure that the infrastructure sustains operational demands throughout its design life and possibly beyond. In this light, effective and sustainable infrastructure maintenance planning and practices must be recognised, prioritised and promoted at all levels of government toward provision of efficient, safe and cost-effective public infrastructure.

\subsection{Understanding the National Infrastructure Maintenance Strategy (NIMS)}

Effective planning, scheduling and budgeting for infrastructure maintenance not only reduce maintenance costs, but also improve utilisation of the maintenance workforce by reducing delays and interruptions and ultimately improve the quality of maintenance work by adopting the best methods and procedures and assigning the best qualified workers for the job [13].

In 2006, the SA Cabinet had recognized the importance of infrastructure maintenance within Government and the role that effective maintenance will play in support of the Accelerated and shared Growth Initiative of South Africa (ASGISA), which was aimed at effective planning, budgeting and implementation of infrastructure and ultimately growing economic development and reducing unemployment. To this end cabinet had approved the NIMS in August 2008 and the Department of Public Works (DPW), the Construction Industry Development Board (CIDB) and the Council for Scientific Research (CSIR) had been tasked with leading the implementation of the programme to deliver on the NIMS strategy [14].

Noting that some public sector institutions' lack of capacity, along with other operational deficiencies, are not likely to improve their maintenance policies and practices. Therefore, a holistic national strategy was required for new and existing infrastructure to be maintained in good working order.

The key focus on the NIMS programme is the facilitation of appropriate intergovernmental coordination between national, provincial and local government, including SOEs in order to institutionalise and implement the recommendations in the NIMS.

The NIMS embraces the following standards and guidelines: "Maintenance Management Standard"; "Maintenance Accounting Framework"; "Maintenance Competency Profiles"; Maintenance Monitoring and Evaluation Protocol; Contractor Development in the Maintenance Industry and the "Maintenance Planning Guideline for Immovable Assets". The purpose of this document is to guide the maintenance management personnel of immovable assets through the preparation of Maintenance Management Plans. 


\subsection{Maintenance hierarchy}

Fig. 1 illustrates the "maintenance hierarchy", whereby the infrastructure maintenance framework is described through segmenting an asset base into appropriate classifications. The asset hierarchy can be based on asset function, asset type, or a combination of both [15].

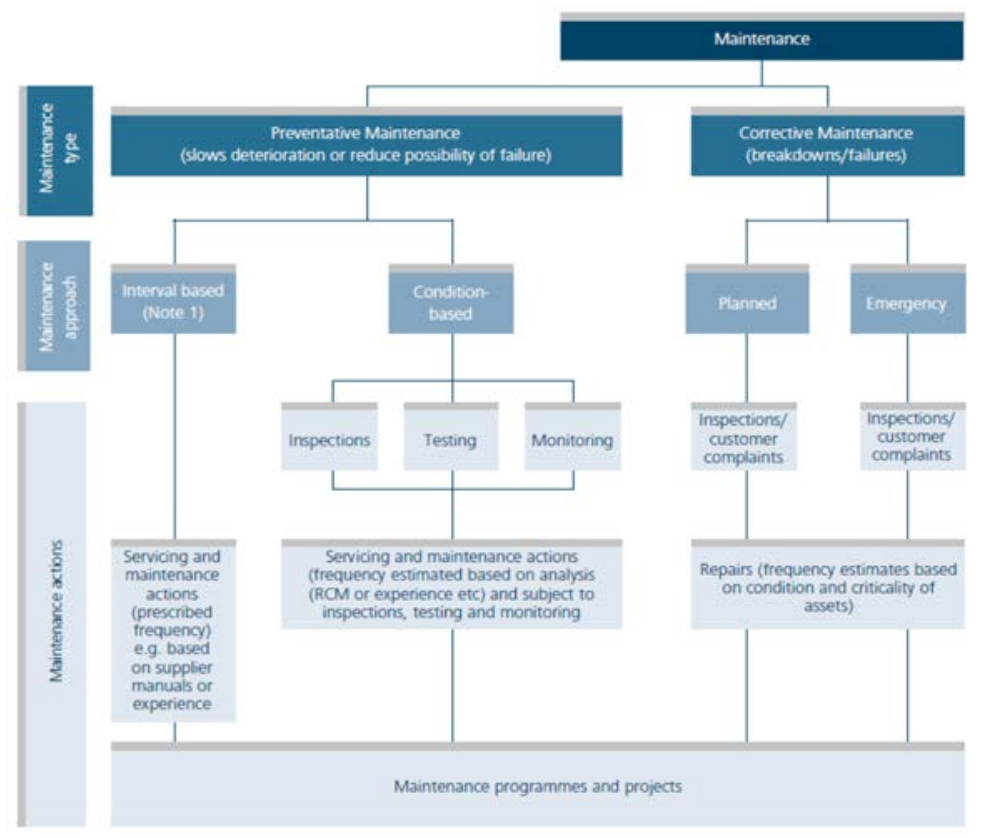

Figure 1: Maintenance management standard for immovable assets. (Source: NIAMM, 2017 [15].)

The sentiment by many South Africans is that public infrastructure maintenance practices generally resides under reactive or emergency maintenance, "fix when broken" approach. With due consideration to the issue of financial instability which exists in many public sector institutions adversely affects the process of good infrastructure maintenance. Although maintenance forecast planning may take place toward establishing asset management plans, certain public institutions may not have the required budget, capacity and or suitable skills to take these plans to fruition.

There is a great need in SA for maintenance practices to embrace the values and advantages of the preventative maintenance type and approach (Fig. 1). This type of maintenance invokes better planning, prolongs infrastructure functionality, aids slower infrastructure deterioration and a reduced possibility of infrastructure failure. Preventative maintenance is perceived to be costly due to the drawn-out operational funding requirements. However preventative maintenance can have cost savings when considering the cost of infrastructure replacement, which may occur much sooner than the anticipated end of design life due to an inadequate maintenance regime. Preventative maintenance approach being a reoccurring practice, involves interval and condition assessment-based interventions which can be a sustained job enabler and to a great extent, can be supportive of socio-economic advances and opportunities. 


\subsection{Explaining the Government Immovable Asset Management Act (GIAMA)}

In support of the NIMS, the Government Immovable Asset Management Act (GIAMA) which was approved in parliament during 2007, established maintenance as a priority from a regulatory standpoint. The main objectives of GIAMA are: To provide a uniform immovable asset management framework to promote accountability and transparency within government; ensure effective immovable asset management within government; ensure coordination of the use of immovable assets with service delivery objectives of a national or provincial department and the efficient utilisation of immovable assets; optimise the cost of service delivery [16].

The aims of GIAMA is to promote better asset management, better keeping of asset registers and link new infrastructure assets to ongoing operational and maintenance budgets. The GIAMA made it obligatory for public sector institutions to draw up sound multi-year infrastructure asset management plans.

\section{PERFORMANCE AND FINANCIAL CONDUCT OF SOES AND MUNICIPALITIES} As highlighted in the "Update on the National infrastructure Maintenance Strategy (NIMS), 2008" - Since the introduction of NIMs and GIAMA over a decade ago, infrastructure in some sectors have shown good performance, yet infrastructure in other sectors are not being appropriately maintained.

Larger institutions seemed to have been performing the best with regard to maintenance, example the Department of Water Affairs and Forestry (DWAF) now known as DWS, Airports Company South Africa (ACSA), Telkom, Eskom, South African National Roads Agency (SANRAL), Transnet and most metropolitan municipalities, while other rural municipalities have failed [17].

However, since 2008, the credibility of many good performing SOEs, including a large number of municipalities progressively deteriorated to a point of weakened financial sustainability and performance.

An analysis on the latest results of South Africa's SOEs shows that most performed satisfactorily in the year to March 2018, however, 13 of the 30 are still performing dismally. Nine of these - Eskom, SAA (South African Airways), SA Express, the SABC (South African Broadcasting Corporation), the Post Office, Denel, roads agency SANRAL, PetroSA and PRASA (Passenger Rail Agency South Africa) - continue to bleed so much cash that they dwarf the positive results from the remaining SOEs. The nine struggling companies posted total losses of nearly R20 billion over the last 12 months [18].

A report by the Auditor General South Africa (AGSA) in 2018 revealed that there were serious weaknesses in the financial management of national and provincial government that had not been addressed - unauthorised expenditure increased by $38 \%$ from the previous year to 2.1 billion $-86 \%$ of which was a result of:

Overspending; fruitless and wasteful expenditure increased by over $200 \%$ from the previous year to R2.5 billion; irregular expenditure remained high at R51 billion - it is worth noting that the R51 billion excludes the SOEs that are not audited by the AGSA, whose total irregular expenditure totalled R28.4 billion; the financial health of auditees have continued to deteriorate; there was an emerging risk of increased litigation and claims against departments; a total deficit of R35.1 billion was incurred by the $41 \%$ of public entities whose expenditure have exceeded their revenue; the auditees that substantially did not comply with legislation increased from $64 \%$ to $72 \%$ [19].

The Auditor General said that the lapse in oversight and controls in the area of compliance was evident in a number of areas, including supply chain management (SCM), and this has 
led to increased irregular expenditure. The non-compliance with SCM legislation had increased - the status was much worse than when compared to the 2014-2015 audit.

The AGSA report lays down the reasons that have contributed to SA infrastructure decline in service delivery and efficiency. It must be iterated that in the past decade (2008-2018), the quality of leadership in majority of the public entities have been poor, lacking appropriate governance and accountability, and as a result have led to the recession in credibility and the functionality of SOEs including many municipalities. The ramification of such includes compromised operations and maintenance practices.

Currently, numerous public institutions circumstances underpin conditions of a state in crisis which create greater risks for a favourable setting toward sustainable infrastructure maintenance practices to prosper. With this perspective in mind, it is anticipated that the National Infrastructure Maintenance Strategy be weighed up on its effectiveness in guiding infrastructure maintenance in the current SA climate. There is a need for an updated approach in strategy and programmes that would have a progressive influence on the prioritization of infrastructure maintenance.

To raise the living standards of people, sustainable economic growth and structural reform is essential to empower disadvantaged communities who must be included in the development process of a dynamic economy. Development programmes and maintenance projects in SA should change from emergency to structured employment-generating maintenance programmes over the long-term. Public spending on infrastructure construction and maintenance can be a valuable policy tool to provide economic stimulus during recessions [20].

An updated infrastructure maintenance strategy should raise existing infrastructure maintenance to a level of importance of new national strategic economic infrastructure, with improved regulations supportive of better planning, execution and monitoring of infrastructure maintenance and service delivery across all public sectors. A revised national infrastructure maintenance strategy should speak to timeous and sustainable asset management planning that is concomitant to job creation and national strategies which promote assured positive social and economic transformation.

\section{INFRASTRUCTURE FUNDING - A KEY CHALLENGE}

New infrastructure, especially strategic economic infrastructure that is in support of the National Development Plan, 2030, need to include funding that resonates with infrastructure life-cycle planning and is inclusive of infrastructure maintenance costs in the long term. All too often, new infrastructure budgeting stray away from maintenance costs. This is due to infrastructure developers who usually hand over the completed infrastructure to public institutions and municipalities who manage the operations thereafter. However, consideration is not given to the dire financial and structural status of many municipalities that may not have available or sufficient budget to execute efficient maintenance of infrastructure in the long term.

For the past few years, since the 2010 Soccer World Cup, there is a diminishing trend of available capital in the market being invested in the public infrastructure portfolio. In the same tone, availability of funding for infrastructure maintenance is also scarce. This intertwined with financially constrained SOEs and municipalities that are struggling to generate sufficient revenue for operations and maintenance, leaves an even wider funding gap to fill.

Securing funding from the market for public infrastructure projects is an arduous task, even more so when infrastructure projects are categorised as social projects or for services to a community that is unable to afford municipal services. With this in mind there seems to be 
a growing trend were SA municipalities are making gains in revenue from property rates being generated from new community developments, and existing developments are given lesser priority. This practice is due to infrastructure maintenance and service delivery backlogs being in communities than cannot afford to pay for municipal services and this leads to poor municipal revenue generation.

Noting the above, warrants the need for a paradigm shift and more innovative thinking on how SOEs and municipalities model revenue generation. Funding institutions and financiers holding public infrastructure bankability in high regard should have a greater appreciation for the social and economic derivatives that would benefit a district [21], a province or the country-if a holistic approach is embraced, and to a lesser extent, place attention on financial returns synonymous with the usual funding models.

South African funding agencies, including SOEs and other public entities which manage various national bulk infrastructure and municipal funding grants should have better understanding of development plans, timelines and policies at a municipal level. There needs to be more supportive intergovernmental relationships and policies that stem from National Treasury to the point of municipalities, and the process in which municipalities are funded needs to be modified to allow for a more conducive economic environment.

\section{OPPORTUNITIES ALONGSIDE TRADITIONAL INFRASTRUCTURE MAINTENANCE}

While the SA economy resides in a state of weakened economic sovereignty, there exist opportunities alongside the traditional infrastructure maintenance for service delivery. Preparation ahead during times of an economic crisis - through proper planning and a clear vision can help capitalise on infrastructure maintenance opportunities that will positively transform the future social and economic landscape.

The following are some examples of sectors, were infrastructure maintenance opportunities can be planned for in enriching the SA economy:

\subsection{Information and Communication Technology (ICT) - opportunities}

Traditional public services like water and electricity are well known as essential economic growth enablers, yet in the modern world, huge economic significance is placed on the ICT sector which does demand appropriate positioning in the public infrastructure sector and in local and global economic value chains.

In light of the fourth Industrial Revolution, this sector is vital in enabling an environment of technology advancements to prevail, as well as a role in skills and industrial development. The South African ICT sector has confirmed good growth, mainly influenced by the mobile sector. However, the national objective of affordable access to the complete range of ICT services is limited. Broadband access, specifically fixed broadband remains very low in communities that need it most. ICT in the public sector space has great opportunities for growth and will demand further skills in the workforce, jobs and entrepreneurial opportunities in the development and maintenance of software, hardware and the ICT services subsectors.

\subsection{Climate change and the environment}

South Africa is experiencing significant effects of climate change particularly as a result of increased temperatures and water variability. Climate change has the potential to redress the gains made on the Millennium Development Goals (MDGs) and impede the country's ability 
to achieve the Sustainable Development Goals (SDGs) and also poses risks to opportunities for socio-economic development [22]. SA's adaption to climate change presents an opportunity to transform the local economy and strengthen the social environment and become more competitive in the African and global marketplace.

Improved planning toward new approaches, materials, research and development into new technologies will ensure that SA's infrastructure is more resilient to climate change. The opportunity for better ways to manage the risks associated with climate change and extreme weather, provides for new opportunities in maintenance techniques that evolve from developments in climate change resilient infrastructure materials and technologies.

\subsection{Construction industry}

The construction industry, specifically the larger more established South African construction companies have been hardest hit due to the economic slowdown, for example Group Five and Basil Read, among others, have filed for business rescue. When this happens a large number of highly skilled engineers and technical staff tend to search for job opportunities that exist outside the country. The infrastructure maintenance strategy should recognise the construction industry crisis as an opportunity in retaining key skills in SA while encouraging growth and stability in the construction industry.

In support of new enterprise development, national infrastructure maintenance strategy should reassure the growth of localised manufacturing of commodities and local services. Integrated supply chain processes should support most, if not all equipment and material needs required for infrastructure maintenance projects with local content products.

Skills development programmes can be enhanced through the infrastructure maintenance strategy, which have genuine learner ship programmes where trainees are guaranteed employment during practical training, which is followed by fixed-term contracting and permanent employment upon completion of training. Agreed, that there have been collaborative efforts between state education institutions, SOEs and the private sector to forge robust skills development programmes, yet ultimately SA suffers a high unemployment rate and skills depletion that worsens quarterly.

Focused synergies between the respective education, public and private institutions need to be reinvigorated for better industrious outcomes, which are aligned to relevant and robust infrastructure maintenance programmes.

\subsection{Urbanisation and population expansion}

The 2012 NIP focused mainly on national economic and social issues, largely overlooking the crucial role played by urban (cities) infrastructure in an increasingly urbanised South Africa. Networked urban infrastructures need to be managed: they must be designed, built, operated and replaced [23]. In reality, cities may be the spaces where these infrastructures are concentrated, but the idealistic image of how the project life cycle, including infrastructure maintenance processes all works, is very far from the true situation.

Increased urbanisation in relation to the Integrated Urban Development Framework (IUDF) [19] should form an integral part of prioritised public infrastructure maintenance programmes in conjunction with the economic levers as specified in the IUDF.

If adequately supported, cities which are economic hubs of a country have the ability to grow steadily year on year. This can be a richly rewarding, long term opportunity for developing the maintenance industry where infrastructure and service delivery is optimised through new infrastructure development (having long term maintenance strategies), replacing 
and maintaining existing infrastructure toward operationally sound service delivery to communities and businesses.

\section{CONCLUSION AND RECOMMENDATIONS}

South Africa is off-track in meeting objectives provided in the 2030 National Development Plan (NDP). This further stagnates South Africa's efforts in contributing to continental and global objectives, such as the United Nations' Sustainable Development Goals by 2030. As such, South Africa in need of fast tracking investigations into optimising national strategies in implementing sustained infrastructure development inclusive of whole life-cycle maintenance practices.

Broadly speaking, much of South Africa's built environment may be in good condition (private sector included), nonetheless, the quality of services being delivered by existing public infrastructure outlines a scenario of low maintenance levels in many sectors. Public entities have not fully embraced long-term planning in infrastructure maintenance. This outlook extends to insufficient funding intertwined with inadequate budgeting for maintenance, inefficient management systems, absence of relevant skilled resources, poor planning and integration amongst public service delivery institutions. These common factors contribute to the deteriorating quality of service delivery that emanate from existing infrastructure, hence contributing to declining social development and economic growth.

Accountability and ownership toward delivery timelines, quality and cost, being fundamental project management principles need to be instilled at all levels of public institutions. It is essential that regulatory frameworks and policies entrench principled and unwavering governance and performance toward asset management planning, costing, financing, budgeting, procuring and maintenance execution. Governance of infrastructure maintenance programmes toward social development and economic growth will need to be firmly observed, managed and monitored at every level within state institutions.

To plan for and adaption of new strategies in targeting maintenance opportunities requires a coordinated approach by government in terms of policy certainty and regulation. Political will need to drive change for an advanced infrastructure maintenance strategy that is fully supportive of socio-economic growth opportunities and a strategy which is adhered to in all public institutions. The political fraternity must recognise the value of revolutionising and elevating the status of infrastructure maintenance to that of new strategic infrastructure development. A transformed maintenance industry should emerge, capable of stimulating a catalytic economic environment. It is imperative that the potential of infrastructure maintenance as a powerful mechanism of economic growth and service delivery is realised and deservedly given precedence as South Africa enters its "New Dawn" [25] in building a brighter future.

\section{REFERENCES}

[1] Adam, S., The Wealth of Nations, 1776.

[2] Presidential Infrastructure Coordinating Commission (PICC), National infrastructure plan (NIP). Report, 2012.

[3] Clarke, R., Procee, P., Brinceño-Garmendia, C., Kikoni, E. \& Kizito, J., Back to Planning: How to close Brazils infrastructure gap in times of austerity, Report No. 117392-BR, 1, July 12, World Bank Group: Viñuela, 2017.

[4] Boshoff, L., Municipal Infrastructure Asset Care in South Africa: A Reality Check, 2009.

[5] Engineering News, Rethinking the value of infrastructure in South Africa. www.engineering news.co.za. Accessed on: 8 Jun. 2019. 
[6] South African Institute of Civil Engineers (SAICE), Infrastructure report card for South Africa.

[7] Australian Infrastructure Audit, Our infrastructure challenges executive summary, April 2015.

[8] National Planning Commission (NPC), National development plan (NDP) 2030.

[9] STATSSA, Electricity infrastructure dominates infrastructure spending. www.statssa.go.za. Accessed on: 17 May 2019.

[10] Crompton, R., Explained: Why Eskom is in so much trouble. www.iol.co.za. Accessed on: 15 May 2019.

[11] Petrus Matji, M. \& Ruiters, C., Appropriate Solutions for Operation and Maintenance Challenges of Water Services Infrastructure in South Africa, 2014.

[12] Department of Water and Sanitation, National water and sanitation plan, vol. 1: Call to action - Ready for the future and ahead of the curve. Project, 9 Mar. 2018.

[13] Construction Industry Development Board (CIDB) \& Department of Public Works (DPW), National immovable asset maintenance management: Maintenance planning guideline for immovable assets.

[14] Department of Public Works (DPW), Construction Industry Development Board (CIDB), Council for Scientific and Industrial Research (CSIR), National infrastructure maintenance strategy (NIMS), Aug. 2008.

[15] National Immovable Asset Maintenance Management (NIAMM), Maintenance management standard for immovable assets.

[16] Government Immovable Asset Management (GIAMA), Act no.19, 2007.

[17] Construction Industry Development Board (CIDB), Update on the national infrastructure maintenance strategy (NIMS), 2008.

[18] Kruger, A., Most state-owned companies show improvement. www.moneyweb.co.za. Accessed on: 29 May 2019.

[19] The Auditor General South Africa (AGSA), Audit results of national and provincial government departments and their entities, 21 Nov. 2018.

[20] Didibhuku Thwalai, W., Challenges Facing Labour-Intensive Public Works Programmes and Projects in South Africa, 2007.

[21] Development Bank South Africa (DBSA), Infrastructure dialogues: Financing municipal infrastructure, how do we bridge the funding gap? Nov. 2018.

[22] Department of Environmental Affairs - 644, National environmental management: Draft national climate change adaptation strategy, 6 May 2019.

[23] Department of Corporate Governance and Traditional Affairs, Integrated urban development framework (IUDF) - Implementation plan 2016, 2019.

[24] Palmer, I. et al., Contribution to the Integrated Urban Development Framework: South Africa's Urban Infrastructure Challenge.

[25] Arnoldi, M., Broad stakeholder engagement necessary to effect 'new dawn' - Cesa. www.engineering news.co.za. Accessed on: 20 Jun. 2019. 